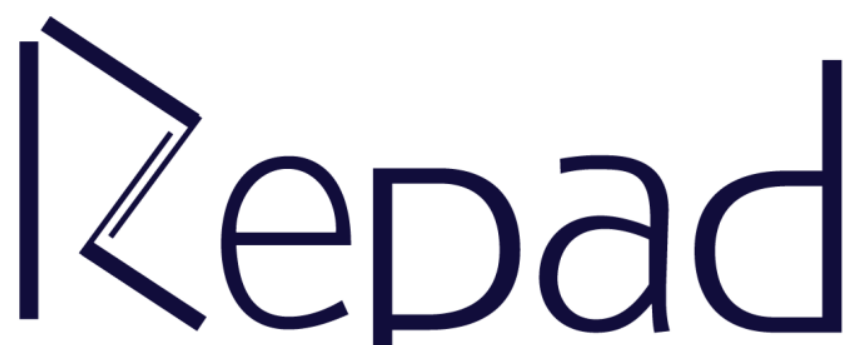

Revista Estudos e

Pesquisas em Administração 


\title{
A RELAÇÃO ENTRE VARIÁVEIS SOCIODEMOGRÁFICAS E UMA MARCA TOP OF MIND DE COSMÉTICOS
}

Jéssyca Lages de Carvalho Castro http://orcid.org/0000-0001-5819-8695

Universidade de Fortaleza Fortaleza-Ceará, Brasil

Renata Torquato de Araújo Pitombeira http://orcid.org/0000-0002-6087-1380

Universidade de Fortaleza Fortaleza- Ceará, Brasil

Macário Neri Ferreira Neto http://orcid.org/0000-0002-9697-4066

Universidade de Fortaleza Fortaleza- Ceará, Brasil

Tiago Morais Caetano http://orcid.org/0000-0002-6870-0519

Universidade de Fortaleza

Fortaleza- Ceará, Brasil

Felipe Albuquerque Sobral e Silva http://orcid.org/0000-0002-1329-0057

Universidade de Fortaleza

Fortaleza- Ceará, Brasil

\begin{abstract}
Resumo
O estudo sobre o comportamento do consumidor é importante para que as empresas construam suas marcas e consquistem consumidores, de forma que possam enfrentar a concorrência e manter a continuidade dos negócios. Nesse sentindo, o presente trabalho tem como objetivo verificar se as variáveis sociodemográficas se relacionam com a marca top of mind para cuidados com os cabelos. Para tanto se utilizou de uma pesquisa descritiva, bibliográfica, do tipo survey e com a utilização de questionários semiestruturados, que foram aplicados em uma amostra não probabilística e por conveniência, sendo os questionários distribuídos com uso das redes sociais e internet. O dados foram tratados estatisticamente com uso do software SPSS $^{\circledR}$ da IBM $^{\circledR}$. Por fim, conclui-se que a marca top of mind da pesquisa é a Pantene e que, de alguma forma, sofre influência das variáveis gênero e renda.
\end{abstract}

Palavras-chave: Marketing. Top of mind. Valor de marca. Comportamento do consumidor. 


\title{
THE RELATION BETWEEN SOCIODEMOGRAPHIC VARIABLES AND A TOP OF MIND COSMETIC BRAND
}

\begin{abstract}
The study on consumer behavior is important for companies to build their brands and reach consumers, so that they can face competition and maintain business continuity. In this sense, the present work aims to verify if the sociodemographic variables are related to the top of mind brand for hair care. For this purpose, a descriptive, bibliographic, survey-type survey was used, using semi-structured questionnaires that were applied to a non-probabilistic and convenience sample, with the questionnaires distributed using social networks and the internet. The data were treated statistically using the IBM® SPSS ${ }^{\circledR}$ software. Finally, it is concluded that the top of mind brand of the research is Pantene and that, in some way, it is influenced by the variables gender and income.
\end{abstract}

Keywords: Marketing. Top of mind. Brand value. Consumer behavior.

Submetido: $14 / 03 / 2020$

Aceito: 05/05/2020

Publicado: $31 / 05 / 2020$

\section{Introdução}

O valor de uma marca retrata uma condição que favorece a resposta do consumidor a sua comercialização, por representar a familiaridade com a marca e trazer lembranças favoráveis e relevantes, que influenciam positivamente a decisão de compra (COBB-WALGREN; RUBLE; DONTHU, 1995; WOOD, 2000; HAKALA; SVENSSON; VINCZE, 2012; KOTLER; KELLER, 2012; SCHIVINSKI; DABROWSKI, 2016).

Uma marca é um mecanismo que, por meio de seus atributos, diferencia o produto ou serviços, fornecendo ao cliente satisfação e benefícios pelos quais eles estão dispostos a pagar, com isso alcançando vantagem competitiva para a empresa (WOOD, 2000). Nesse contexto, tem-se a marca top of mind, que é a primeira marca que vem à mente quando perguntado a uma pessoa ou grupo de consumidores, quando pensam em várias categorias de produtos (HAKALA; SVENSSON; VINCZE, 2012). Embora o fato de ser top of mind não garanta ocupar o mesmo espaço no mercado, ser uma marca lembrada pelas pessoas colabora para entender o comportamento do consumidor, conhecer fatores que influenciam o consumo e a lembrança da marca. Ademais, o comportamento do consumidor é uma área essencial do marketing e, por isso se faz necessário o seu estudo, que é definido como um estudo com pessoas, grupos e organizações, visando compreensão de como esses se predispõem para consumo, envolvendo todo o processo de decisão, desde a escolha, uso e descarte de produtos ou serviços, para fins de satisfação de suas necessidades e desejos (VEIRA, 2002; KOTLER; KELLER, 2012).

Nesse sentido, o comportamento do consumidor é influenciado por diversos fatores culturais, socioeconômicos, fisiológicos, ambientais e psicológicos, que podem interferir em sua decisão de compra, isso ocorrem em decorrência de convivência em sociedade, em que são compartilhadas opiniões e experiências entre as pessoas (KOTLER; KELLER, 2012; CERQUEIRA et al., 2013). 
Portanto, este trabalho busca verificar se as variáveis sociodemográficas se relacionam com a marca top of mind para cuidados com os cabelos. A delimitação do estudo decorre da importância do segmento de higiene pessoal, perfumaria e cosméticos na economia brasileira, pois de acordo com a ABHIPEC, o setor gera 125 mil empregos e conta com um faturamento superior a 30 bilhões de dolares ${ }^{1}$.

Para se alcançar o objetivo proposto foram aplicados questionários para duzentos e um respondentes, após a coleta foram tabulados e analisados os dados através da utilização do software SPSS da IBM $^{\circledR}$. A análise contou com técnicas de correlação e regressão linear com a finalidade de identificar a existência entre os produtos e os dados sociodemográficos dos respondentes. A pesquisa é relevante por contribuir com mais informações sobre o tema e para preencher a lacuna existente sobre trabalhos que buscam relacionar a marca com as características sociodemográficas dos indivíduos.

Além desta introdução, este artigo apresenta seções: a segunda e terceira apresentam a revisão da literatura sobre comportamento do consumidor e marca, respectivamente. A quarta apresenta alguns trabalhos correlatos. A quinta seção apresenta a metodologia da pesquisa, a sexta se refere à apresentação e discussão dos resultados e a sétima encerra o trabalho com as conclusões derivadas dessas análises.

\section{O Comportamento do Consumidor}

O consumidor é influenciado por vários fatores no momento de decidir pela compra de um produto ou serviço, sendo fatores internos e externos que determinam o comportamento do consumidor em busca da satisfação de uma necessidade.

Nesse sentido, entende-se por necessidade os requisitos essenciais para a sobrevivência humana (água, comida, ar, abrigo etc.), que se tornam desejos quando visam produtos ou serviços que possam satisfazê-la. A satisfação se refere aos sentimentos agradáveis ou desagradáveis da pessoa, que surgem da comparação de sua função mental com suas expectativas. Se o desempenho do produto for menor que o esperado, o cliente ficará insatisfeito. Se o produto parece estar dentro das expectativas, o cliente está satisfeito; e se o desempenho do produto exceder as expectativas, o cliente está altamente satisfeito ou, em outras palavras, satisfeito (DEHGHAN; ALIZADEH; MIRZAEI-ALAMOUTI, 2015).

A necessidade de satisfazer um desejo gera a demanda, quando há possibilidade de adquiri-lo (KOTLER; KELLER, 2012). Assim sendo, "para os profissionais de marketing, entender o processo que envolve a decisão do consumo é uma tarefa essencial para formular estratégias que posicionem empresas frente à concorrência" (OLIVEIRA; MOREIRA NETO, 2016, p. 35), pois, "como cada consumidor tem personalidade e percepção próprias, saber como identificá-las e compreendê-las é tarefa que exige vários tipos de estudos aprofundados" (VIEIRA, 2002, p. 220).

Todos os dias pessoas tomam decisões motivadas por situações que as acometem, tão rotineiras que nem pecebem. Nesse sentido, o comportamento do consumidor estabelece como os indivíduos, os grupos, as empresas, as organizações escolhem, compram, utilizam e, depois, descartam produtos, serviços, ideias ou experiências para responder suas vontades e necessidades (KOTLER; KELLER, 2012). Ademais, conforme demonstrado na Figura 1, no momento da compra esse

\footnotetext{
${ }^{1}$ ABIHPEC - Associação Brasileira da Indústria de Higiene Pessoal, Perfumaria e Cosméticos.
} 
comportamento sofre influência de fatores sociais, culturais, pessoais e psicológicos na busca da satisfação que este consumo oferece (MOURA, 2018; MATTEI; MACHADO; OLIVEIRA, 2006).

Figura 1. Fatores que influenciam no comportamento do consumidor

\begin{tabular}{|l|}
\hline \multicolumn{1}{|c|}{ Fatores Culturais } \\
\hline Cultura \\
Subculturas \\
Classes Sociais \\
\hline
\end{tabular}
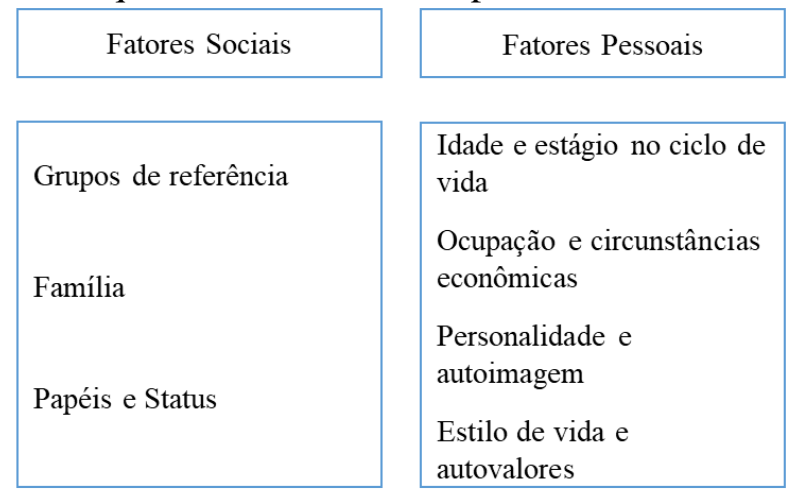

Fatores Psicológicos

Fonte. Kotler e Keller (2012)

Os fatores culturais são os que mais exercem influência na decisão de compra, sendo originados dos desejos e comportamentos das pessoas, sendo a família, as instituições, os valores, as classes sociais e as subculturas como nacionalidade, religião, entre outros. Os fatores sociais estão relacionados aos grupos que o indivíduo pertence, a sua familia da qual recebe orientações de comportamento, bem como participam das decições de compra, além do status que aquela aquisição pode trazer. Os fatores pessoais se referem a sua idade, sexo, situação financeira, personalidade, autoimagem, estilo de vida, ou seja, de como a pessoa se encontra no meio social. E, os fatores psicológicos que caracterizam o indivíduo pelas influências que recebem dos estímulos do marketing, o que ele percebe e o motiva a exercer a compra (KOTLER; KELLER, 2012).

Outro fator importante é a conscientização ambiental, o processo decisório dos consumidores está sujeito às influências de entidades e líderes ambientalistas, que influenciam a maneira de pensar e agir desssas pessoas que passam a ter preocupação ambiental cada vez mais presentes, exigindo responsabilidade de seus fornecedores (ROBERTS, 1996; GARCIA et al., 2008).

Nesse sentido, uma ampla compreensão desses fatores se reveste de grande importância para o entendimento sobre o comportamento do consumidor, tendo essas habilidades específicas levado os profissionais do marketing a estudar e conhecer a conduta de compra do consumidor (LEVRINI; MACIEL, 2016). Além do mais, o processo de consumo abarca diversos estágios e atitudes, atualmente os consumidores se valem da internet, seja nas redes sociais ou sites especializados, como forma de buscar informações sobre produtos ou serviços que desejam adquirir, bem como propagar experiências boas ou ruins de consumo, recomendar marcas favoritas ou promover boicotes às marcas indesejadas (COVALESKI; COSTA, 2014).

\section{Marca}

A existência da marca serve, basicamente, para distinguir um produto de outro, ou seja, discernir o que é produzido e seus respectivos fabricantes (SCHARF; SORIANO-SIERRA; PRIM, 2007). 
A American Marketing Association (AMA) conceitua marca como "um nome, termo, sinal, símbolo ou design, ou uma combinação de tudo isso, destinado a identificar os bens ou serviços de um fornecedor ou de um grupo de fornecedores para diferenciá-los dos de outros concorrentes" (KOTLER; KELLER, 2012, p. 258). Em outro conceito, marca é definida como elementos que representam a promessa por parte de uma entidade ou indivíduo aos consumidores de busca satisfação das necessidades surgidas em adquirir produtos ou serviços com os quais os compradores se sintam identificados (GUTIÉRREZ, 2015).

Nesse sentido, a criação de uma marca tem início com procedimentos estratégicos, que inclui estudos de impacto ambiental, do comportamento do consumidor, dos concorrentes e de uma autoanálise, ou seja, são informações que subsidiarão os traços da identidade da nova marca (AAKER, 1998). Ainda, de acordo com o mesmo autor, a identidade da marca é a imagem que se espera de uma marca, que surja na mente dos consumidores quando essa for mencionada. Ademais:

Um dos ativos intangíveis mais valiosos de uma empresa é sua marca, e compete ao marketing gerenciar adequadamente seu valor. Desenvolver uma marca forte é tanto uma arte quanto uma ciência. Requer planejamento cuidadoso e profundo comprometimento de longo prazo, além de um marketing planejado e executado com criatividade. Marcas fortes geram intensa fidelidade do consumidor e sua essência é um excelente produto (KOTLER; KELLER, 2012, p. 257).

As marcas fortes podem usufruir de diversas vantagens que induzem positivamente em sua avaliação, esses benefícios geram um maior retorno financeiro que trará certa tranquilidade à empresa nos períodos de vendas mais baixas (CASTRO; GOUVÊA, 2014), ou seja, se a força da marca é o grau de fidelidade a uma marca e o valor da marca se baseia nos ganhos futuros por essa gerados, quanto maior a força da marca, maior o valor da marca, com isso, implicando em uma garantia de fluxos de caixa futuros (WOOD, 2000).

Ademais, a marca não tem poder, seus consumidores pelo conhecimento e uso do produto/serviço atribuem certa dose de autoridade, influências e outras características baseadas nas experiências do relacionamento com a marca, sendo essas características elementos que conduzem o relacionamento da marca e seu consumidor (SEMPREBON; PRADO, 2016).

A marca representa a soma das qualidades e defeitos, sendo uma ligação simbólica e afetiva entre uma empresa e as pessoas que essa quer atender. A marca absorve as sensações dos consumidores e se transforma em conceitos na mente das pessoas, ocupando um lugar seguro na memória do consumidor (CASTRO; GOUVÊA, 2014). Nesse sentido, Cobb-Walgren, Ruble e Donthu (1995) demonstraram que o valor da marca aumenta as preferências do consumidor e as intenções de compra.

Para Aaker (1992), são cinco os ativos que fornecem valor à marca:

1. Lealdade à marca.

2. Reconhecimento da marca.

3. Qualidade da marca percebida.

4. Associações de marca, além da qualidade percebida.

5. Outros ativos de marca proprietária - por exemplo, patentes, marcas comerciais, relacionamentos de canal. 
Em condições de conhecimento, uma marca pode integrar em um determinado momento, um dos quatro grupos para cada consumidor: i) desconhecida, quando a marca em apreço é estranha aos consumidores; ii) reconhecida, quando é conhecida após a promoção de estímulos; iii) lembrada, quando a marca é reconhecida sem a obrigação de incetivos; e, iv) top of mind, quando é a primeira marca recordada ao se abordar uma determinada categoria de produtos (AAKER, 1998).

Possuir credibilidade não quer dizer que não ocorrerão falhas, mas a maneira como lidam com essas é fundamental para a preservação da marca, portanto, para manter a confiança de seu consumidor, as empresas devem continuar trabalhando para diminuir os erros, pois o sucesso ou fracasso da marca depende da satisfação de seus clientes (COVALESKI; COSTA, 2014). Pois, para o fabricante, o valor da marca oferece uma vantagem diferencial que permite a empresa gerar maior volume e maiores margens. O valor da marca fornece uma forte plataforma para a introdução de novos produtos e isola a marca dos ataques competitivos (COBB-WALGREN; RUBLE; DONTHU, 1995).

Portanto, os clientes que estão satisfeitos ou muito satisfeitos com a compra de um determinado vendedor estão menos dispostos a mudar de fornecedor e a comprar os itens necessários de outras fontes. Grande prazer ou satisfação não apenas causa a preferência lógica, mas também cria um apego emocional à marca do produto (DEHGHAN; ALIZADEH; MIRZAEI-ALAMOUTI, 2015).

Conforme descrito, pelos autores acima, fica evidente que uma marca bem trabalhada, que traga satisfação e que encante seus consumidores, resulta em fidelidade deste cliente e, consequentemente, melhora o fluxo e a previsibilidade do caixa, mas para que isso aconteça as empresas devem manter sua credibilidade e bom relacionamento com seus compradores.

\section{Outros Trabalhos}

$\mathrm{Na}$ literatura não foram localizados trabalhos que demonstrassem a relação entre a marca mais lembrada com variáveis sociodemográficas, portanto, nesta seção, apresentam-se pesquisas semelhantes que possam contribuir para a análise dos dados desta pesquisa.

Com o objetivo de conhecer o grau de associação existente entre o recall de marca e o seu market share, Olliveira e Gouvêa (2012) analisaram, com uso da técnica estatística de correlação, a pesquisa "top of mind" realizada anualmente pelo Datafolha. Verificaram a existência de correlação positiva de grau moderado entre as variáveis, "reiterando os preceitos teóricos de que a fixação de uma marca de maneira clara e distinta pode contribuir para a obtenção de resultados positivos em termos de participação de mercado" (OLLIVEIRA; GOUVÊA, 2012, p. 28).

Com a finalidade de avaliar a preferência do consumidor em relação aos atributos de cosméticos faciais anti-idade que as marcas influenciam, Castro e Gouvêa (2014) pesquisaram, durante o ano de 2009, as preferências de cem mulheres em relação aos cosméticos anti-idade. Descobriu-se que, para a amostra estudada, os atributos determinativos da escolha de um creme facial anti-idade, dispostos em ordem crescente, perfazem a seguinte escala: quantidade mínima de compra, status, preço, tipo de marca e qualidade.

A pesquisa de Cerqueira et al. (2013) teve como foco analisar a percepção dos consumidores e vendedores sobre o processo de compra de cosméticos, o estudo foi 
composto por entrevistas e aplicação de questionários com vendedores de cosméticos na cidade de Aracaju (SE). Foram aplicados duzentos e dezesseis questionários e realizadas treze entrevistas. Concluíram que o comportamento de compra dos consumidores ocorre a partir de um processo de busca de informações e benefícios percebidos.

Com o objetivo de verificar a mudança de percepção do consumidor de algumas marcas, que estavam no topo do mercado colombiano no período entre 2008 e 2013 e que foram perdidas por processos de compra, de fusão ou de absorção de outra marca, Gutiérrez (2015) aplicou questionários a quinhentos e quarenta respondentes na cidade de Bogotá. O estudo mostrou as características que os consumidores mais valorizam em relação a uma marca e como o gerenciamento adequado da marca mesclada, comprada ou absorvida pode resultar na consolidação e no posicionamento da nova marca.

\section{Métodos}

A pesquisa é classificada quanto aos seus objetivos como descritiva, utilizada quando o pesquisador deseja descrever os fatos sem intervir. Quanto à natureza se trata de estudo quantitativo com uso de dados tratados estatisticamente, originados a partir de um questionário utilizado como técnica de coleta de dados (DALFOVO; LANA; SILVEIRA, 2008; PRODANOV; FREITAS, 2013). A coleta de dados foi disponibilizada online, por meio das redes sociais, durante o mês de março/2019, na cidade de Fortaleza-CE.

Responderam a pesquisa duzentas e uma pessoas, caracterizando a amostra como não probabilística e por conveniência, o tamanho da amostra atende as recomendações de Hair Jr. et al. (2009), que se tenha no mínimo de cinco a dez respondentes por variáves. Os questionários foram tabulados e analisados por meio do software SPSS - Statistical Package for the Social Sciences, versão 23.

O questionário apresentava perguntas sociodemográficas e questões relacionadas às dimensões lealdade e força da marca.

\section{Análise e Discussão}

O conhecimento das características demográficas da amostra é útil, pois ajuda a definir características gerais da população estudada para outros pesquisadores. Além disso, esse conhecimento torna as informações obtidas neste estudo úteis para generalizar os resultados para outra população ou modelo de perguntas para pesquisas futuras (DEHGHAN; ALIZADEH; MIRZAEI-ALAMOUTI, 2015). Quanto ao gênero, a amostra contou com $75,1 \%$ dos respondentes do sexo feminino, valores similares aos encontrados na Pesquisa do Perfil do Consumidor de beleza e bem-estar em Santa Catarina $(2018)^{2}$, que apresentou $70,41 \%$ de seus respondentes do gênero feminino. A Tabela 1 apresenta os resultados referentes às faixas etárias, que apresentaram uma predominância da faixa de 31 a 35 anos. Considerando a idade até os 40 anos, resultou em 78,1\% da amostra. A pesquisa do Sebrae (2018) apresentou 71,1\% na mesma faixa.

A Tabela 2 demonstra os dados referentes à escolaridade dos respondentes, perecebe-se que a maioria $(54,7 \%)$ tem a escolaridade em âmbito de pós-graduação. Esses valores podem ser explicados pela localização na qual ocorreu a pesquisa, que foi em uma área nobre de Fortaleza.

\footnotetext{
${ }^{2}$ Disponível em < https://atendimento.sebrae-sc.com.br/inteligencia/analise-diagnostica-de-

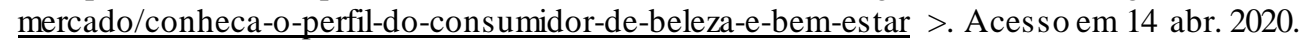


Com relação à renda familiar, a Tabela 3 demonstra os resultados nos quais se percebe que mais de $50 \%$ estão com renda superior a cinco salários mínimos, também explicada pela localização de início da pesquisa.

Tabela 1. Faixa-etária

\begin{tabular}{c|c|c}
\hline Faixa etária & Frequência & Frequência Relativa \\
\hline 18 a 25 anos & 41 & $20,4 \%$ \\
26 a 30 anos & 28 & $13,9 \%$ \\
31 a 35 anos & 51 & $25,4 \%$ \\
36 a 40 anos & 37 & $18,4 \%$ \\
Acima de 41 anos & 44 & $21,9 \%$ \\
\hline
\end{tabular}

Fonte. Dados da pesquisa (2019)

Tabela 2. Escolaridade

\begin{tabular}{l|c|c}
\hline \multicolumn{1}{c|}{ Variável } & Frequência & Frequência Re lativa \\
\hline Ensino Fundamental Incompleto & 3 & $1,5 \%$ \\
Ensino Fundamental Completo & 2 & $1,0 \%$ \\
Ensino Médio Incompleto & 4 & $2,0 \%$ \\
Ensino Médio Completo & 10 & $5,0 \%$ \\
Ensino Superior Incompleto & 14 & $7,0 \%$ \\
Ensino Superior Completo & 58 & $28,9 \%$ \\
Pós-Graduado & 110 & $54,7 \%$ \\
\hline
\end{tabular}

Fonte. Dados da pesquisa (2019)

Tabela 3. Faixa de renda

\begin{tabular}{l|c|c}
\hline \multicolumn{1}{c|}{ Variável } & Frequência & Frequência Re lativa \\
\hline Até 1/2 salário mínimo & 10 & $5,0 \%$ \\
Mais de 1/2 a 1 salário mínimo & 4 & $2,0 \%$ \\
Mais de 1 a 2 salários mínimos & 18 & $9,0 \%$ \\
Mais de 2 a 3 salários mínimos & 31 & $15,4 \%$ \\
Mais de 3 a 5 salários mínimos & 25 & $12,4 \%$ \\
Mais de 5 a 10 salários mínimos & 38 & $18,9 \%$ \\
Mais de 10 salários mínimos & 64 & $31,8 \%$ \\
Sem declaração & 11 & $5,5 \%$ \\
\hline
\end{tabular}

Fonte. Dados da pesquisa (2019)

Em seguida, foi solicitado aos respondentes que indicassem qual a primeira marca de produtos para cabelo que viesse a sua cabeça. A Tabela 4 demonstra as marcas mais lembradas pelos participantes da pesquisa. Saliente-se, ainda, que as marcas lembradas não são de um único produto, mas de vastas linhas de cosméticos.

Conforme demonstrado na Tabela 4, a marca Pantene foi a mais lembrada para $31,8 \%$ dos respondentes, em seguida vem a marca Elseve com 25,4\%. As marcas top of mind ou referenciais, neste caso representadas pelas marcas dos fabricantes, se caracterizam pela forte identidade contruída pelo conhecimento tecnológico e compreensão das necessidades do mercado (CASTRO; GOUVÊA, 2014). 
Tabela 4. Marca top of mind

\begin{tabular}{c|c|c|c|c}
\hline Marca & $\begin{array}{c}\text { Quantidade de } \\
\text { Produtos da Marca }\end{array}$ & Fabricante & Frequência & $\begin{array}{c}\text { Frequência } \\
\text { Relativa }\end{array}$ \\
\hline Pantene & 127 & Procter \& Gamble & 64 & $31,8 \%$ \\
Elseve & 89 & L'Oréal & 51 & $25,4 \%$ \\
Seda & 222 & Unilever & 30 & $14,9 \%$ \\
TRESemmé & 65 & Unilever & 24 & $11,9 \%$ \\
Dove & 435 & Unilever & 23 & $11,4 \%$ \\
Outras marcas & & & 9 & $4,6 \%$ \\
Totais & & & 201 & $100 \%$ \\
\hline
\end{tabular}

Fonte. Dados da pesquisa (2019)

As questões seguintes estão relacionadas às marcas lembradas pelos participantes, como forma a aferir a lealdade à marca top of mind (Tabela 5).

Tabela 5. Lealdade à marca top of mind

\begin{tabular}{l|c|c|c}
\hline Variável & Resposta & Frequência & $\begin{array}{c}\text { Frequência } \\
\text { Relativa }\end{array}$ \\
\hline Você já comprou um produto da marca para seu & Sim & 178 & $88,6 \%$ \\
cabelo & Sim & 166 & $82,6 \%$ \\
Você já comprou outro produto da marca lembrada & $\operatorname{Sim}$ & 132 & $65,7 \%$ \\
Você usa/possui atualmente um produto da marca & Sim & 159 & $79 \%$ \\
lembrada & Totais &
\end{tabular}

Fonte. Dados da pesquisa (2019)

De acordo com o demonstrado na Tabela 5, os resultados apresentam uma forte lealdade à marca, em que $65,7 \%$ afirmaram possuir um produto da marca lembrada. Nesse sentido, a marca está ligada ao sentimento, a subjetividade do consumidor, sendo diferente do produto pois possui o poder de alcançar indivíduos de diferentes nichos de mercados (OLLIVEIRA; GOUVÊA, 2012). A Tabela 6 demonstra a força da marca para os respondentes, as questões do tipo Likert visavam identificar a satisfação do cliente com a marca lembrada. Como forma de testar a confiabilidade do questionárioo foi efetuado o cálculo do alfa de Cronbach, que resultou no valor de 0,731. Para Hair Júnior (2014), valores acima de 0,7 são considerados ideais para pesquisas, pois demonstra a confiabilidade do instrumento.

Tabela 6. Força da marca top of mind (\%)

\begin{tabular}{l|c|c|c|c|c}
\hline Variável & DT & D & IN & C & CT \\
\hline $\begin{array}{l}\text { Faz sentindo comprar a marca lembrada, mesmo havendo } \\
\text { produtos iguais de outras marcas? }\end{array}$ & 11,4 & 24,9 & 20,4 & 36,8 & 6,5 \\
$\begin{array}{l}\text { Faz sentindo comprar a marca lembrada, mesmo havendo } \\
\text { produtos semelhantes de outras marcas? }\end{array}$ & 8,5 & 21,9 & 15,4 & 47,8 & 6,5 \\
$\begin{array}{l}\text { Faz sentindo comprar a marca lembrada, mesmo havendo } \\
\text { produtos tão bons de outras marcas? }\end{array}$ & 5,0 & 20,9 & 18,4 & 45,3 & 10,4 \\
Faz sentindo comprar a marca lembrada, mesmo havendo \\
produtos semelhantes com preços menores
\end{tabular}

Fonte. Dados da pesquisa (2019) Nota. DT = Discordo totalmente; D = Discordo; IN = Indeciso; $\mathrm{C}=\mathrm{Concordo}, \mathrm{e} ; \mathrm{CT}=$ Concordo totalmente. 
A Tabela 6 demonstra que 52,3\% das respostas concordam, de alguma forma, com as assertivas, demonstrando a força da marca para os pesquisados. Para análise da correlação de Pearson há necessidade de que as variáveis sejam quantitativas (discreta e contínuas) e os valores devem estar normalmente distribuídos. A Tabela 7 apresenta os resultados do teste paramétrico de normalidade Kolmogorov-Smirnov. Conforme demonstrado na Tabela 7 , os valores de $\mathrm{p}<0,05$, portanto, não apresentam normalidade na distribuição, haja vista que os dados não são normalmente distribuídos, foram aplicados testes não paramétricos para testes de hipóteses. A Tabela 8 demonstra o resultado do teste qui quadrado de associação entre duas variáveis.

Para as variáveis gênero e renda, os valores de $p<0,05$, neste caso as variáveis apresentam uma associação significativa com a marca Pantente. Para as variáveis escolaridade e faixa etária, os valores de $\mathrm{p}>0,05$, não sendo possível concluir que as variáveis estão associadas à variável marca, neste caso os resultados obtidos não trazem evidência de qualquer diferença significativa no comportamento (HAIR JR. et al., 2009; CORRAR; PAULO; DIAS FILHO, 2017). A Tabela 9 demonstra que há mais casos do que o esperado nas relações: Pantene e feminino; Pantene e Ensino Superior incompleto; Pantene e Ensino Superior; Pantene e renda de 2 a 3 salários mínimos; e Pantene e idade de 31 a 35 anos.

Tabela 7. Teste de normalidade Kolmogorov-Smirnov

\begin{tabular}{l|c|c|c}
\hline Variável & Estatística & Df & Sig. (valor de p) \\
\hline Pantente & 0,434 & 201 & 0,000 \\
Gênero & 0,468 & 201 & 0,000 \\
Faixa etária & 0,146 & 201 & 0,000 \\
Escolaridade & 0,290 & 201 & 0,000 \\
Renda & 0,175 & 201 & 0,000 \\
\hline
\end{tabular}

Fonte. Dados da pesquisa (2019)

Tabela 8. Teste qui-quadrado - marca Pantene

\begin{tabular}{l|c|c|c}
\hline Teste & Valor & Df & Sig. \\
\hline Gênero & 5,875 & 1 & 0,015 \\
Escolaridade & 8,159 & 6 & 0,227 \\
Renda & 16,480 & 7 & 0,021 \\
Faixa etária & 2,180 & 4 & 0,703 \\
\hline
\end{tabular}

Fonte. Dados da pesquisa (2019)

Tabela 9. Teste qui-quadrado de referência cruzada

\begin{tabular}{|c|c|c|c|c|c|}
\hline \multicolumn{2}{|l|}{ Gênero } & \multicolumn{2}{|r|}{ Masculino } & \multicolumn{2}{|c|}{ Feminino } \\
\hline \multirow{2}{*}{ Pantene } & Contagem & \multicolumn{2}{|r|}{9} & \multicolumn{2}{|c|}{55} \\
\hline & Contagem Esperada & \multicolumn{2}{|r|}{15,9} & \multicolumn{2}{|c|}{48,1} \\
\hline \multicolumn{2}{|c|}{ Escolaridade } & Ensino Médio & Ensino Superior incompleto & Ensino Superior & Pós-graduação \\
\hline \multirow{2}{*}{ Pantene } & Contagem & 1 & 5 & 23 & 32 \\
\hline & Contagem Esperada & 3,2 & 4,5 & 18,5 & 35 \\
\hline \multicolumn{2}{|c|}{ Renda (salários mínimos) } & 2 a 3 & 3 a 5 & 5 a 10 & 10 \\
\hline \multirow{2}{*}{ Pantene } & Contagem & 11 & 6 & 15 & 20 \\
\hline & Contagem Esperada & 9,9 & 8 & 12,1 & 20,4 \\
\hline \multicolumn{2}{|c|}{ Faixa etária (anos) } & Até 30 & 31 a 35 & 36 a 40 & 41 \\
\hline \multirow{2}{*}{ Pantene } & Contagem & 21 & 18 & 11 & 14 \\
\hline & Contagem Esperada & 22 & 16,2 & 11,8 & 14 \\
\hline
\end{tabular}

Fonte. Dados da pesquisa (2019) 


\section{Considerações Finais}

Este trabalho teve como objetivo verificar se as variáveis sociodemográficas se relacionavam com a marca top of mind para cuidados com os cabelos. A pesquisa contou com uma amostra predominantemente feminina, com alta escolaridade e renda elevada.

Após as análises estatísticas, algumas conclusões podem ser tiradas: a) a marca Pantene foi a mais lembrada por $31,8 \%$ dos respondentes; b) em média, $79 \%$ dos respondentes demonstraram fidelidade à marca Pantene; c) a força da marca Pantene foi atestada por 52,3\% dos respondentes; d) com relação à marca Pantene para as variáveis escolaridade e faixa etária, os dados não mostram evidência de associação entre essas variáveis e a variável Pantente, na população em estudo. Em outras palavras, a diferença verificada na amostra, entre a proporção de respondentes que usam Pantene, pode ser explicada meramente por variações casuais da amostragem; e, e) com relação às variáveis gênero e renda, verificou-se que a probabilidade de significância $p$ é inferior a 0,05 . O teste qui-quadrado mostrou que essas variáveis são diferentes quanto ao uso dos produtos da marca Pantene, demonstrando a associação entre as variáveis.

Por fim, conclui-se que a marca top of mind da pesquisa é a Pantene e que, de alguma forma, sofre influência das variáveis gênero e renda.

Como limitações da pesquisa se tem a baixa produção de trabalhos semelhantes no que dificulta as comparações e para pesquisas futuras se sugere que a amostra represente melhor os estratos sociais e os níveis de escolaridade como forma de replicar o presente estudo, também se sugere a aplicação da pesquisa com outros segmentos de produtos.

\section{REFERÊNCIAS}

AAKER, D. A. The Value of Brand Equity. Journal of Business Strategy, v. 13 n. 4, p. 27 - 32, 1992. DOI: https://doi.org/10.1108/eb039503

AAKER, D. A. Marcas: Brand Equity: gerenciando o valor da marca.10 ed. São Paulo: Elsevier, 1998, 309 p.

CASTRO, L. A. M. H. de M.; GOUVEA, M. A. Avaliação da influência do tipo de marca na decisão de compra. REGE-Revista de Gestão, São Paulo, v. 21, n. 2, p. 235 251, abr-jun. 2014. DOI: https://doi.org/10.5700/rege528

CERQUeIRA, A. C. de; OLIVEIRA, R. C. R. de; HOMÓRIO, J. B.; BERGAMO, F. Comportamento do consumidor de cosméticos: um estudo exploratório. Revista Formadores, Cachoeira, v. 6, n. 1, p. 128, nov. 2013.

COBB-WALGREN, C. J.; RUBLE, C. A.; DONTHU, N. Brand equity, brand preference, and purchase intent. Journal of advertising, v. 24, n. 3, p. 25-40, 1995. DOI: https://doi.org/10.1080/00913367.1995.10673481

COHEN, J. Statistical Power Analysis for the Behavioral Sciences. 2 ed. New York: Psychology Press, 1988. 
CORRAR, L. J.; PAULO, E.; DIAS FILHO, J. M. (Org.). Análise multivariada: para os cursos de Administração. Ciências Contábeis e Economia. São Paulo: Atlas, 2017.

COVALESKI, R. L.; COSTA, S. A. Humanização do discurso das marcas diante das novas experiências de consumo. Revista Gestão e Desenvolvimento, v. 11, n. 1, janjun. 2014. DOI: https://doi.org/10.25112/rgd.v11i1.117

DALFOVO, M. S.; LANA, R. A.; SILVEIRA, A. Métodos quantitativos e qualitativos: um resgate teórico. Revista interdisciplinar científica aplicada, Blumenau, v. 2, n. 3, p. 1-13, 2008.

DEHGHAN, A. N.; ALIZADEH, H.; MIRZAEI-ALAMOUTI, S. Exploring the customer perceived values as antecedent of purchase behavior. Serbian Journal of Management, v. 10, n. 2, p. 173-188, 2015. DOI: https://doi.org/10.5937/sjm10-7844

GARCIA, M. N. et al. Inovação no comportamento do consumidor: recompensa às empresas socioambientalmente responsáveis. RAI-Revista de Administração e Inovação, São Paulo, v. 5, n. 2, p. 73-91, 2008.

GUTIÉRREZ, L. M. R. Estudio de cambio en la percepción del consumidor de marcas top of mind en el mercado colombiano. Poliantea, Bogotá, v. 10, n. 18, p. 113-142, janun. 2015. DOI: http://dx.doi.org/10.15765/plnt.v10i18.535

HAIR JÚNIOR, J. F.; BLACK, W. C. BABIN, B. J. ANDERSON, R. E.; TATHAM R. L. Análise multivariada de dados. São Paulo: Bookman Editora, 2009.

HAKALA, U.; SVENSSON, J.; VINCZE, Z. Consumer-based brand equity and top-ofmind awareness: a cross-country analysis. Journal of Product \& Brand Management, v. 21, n. 6, p. 439-451, set. 2012. DOI: https://doi.org/10.1108/10610421211264928

KOTLER, P.; KELLER, K. L. Administração de Marketing. São Paulo: Pearson, 2012.

LEVRINI, G. R.; MACIEL, G. Fatores de influência no processo de compra de serviço de turismo por idosos. Marketing \& Tourism Review, Belo Horizonte, v. 1, n. 1, out. 2016. DOI: https://doi.org/10.29149/mtr.v1i1.3715

MARCONI, M. A.; LAKATOS, E. M. Metodologia Científica. 7. ed. São Paulo: Atlas, 2019. 373 p.

MATTEI, D.; MACHADO, M.; OLIVEIRA, P. A. Comportamento do consumidor: fatores que influenciam no processo de decisão de compra dos consumidores finais. Maringá Management, Maringá, v. 3, n. 2, jul-dez. 2006.

MOURA, R. G. Comportamento do consumidor: A influência da embalagem no processo de decisão de compra das mulheres na aquisição de cosméticos nos supermercados. REA-Revista Eletrônica de Administração, Franca, v. 16, n. 1, p. 424, jan-jun. 2018. 
OLLIVEIRA, B.; GOUVÊA, M. A. O relacionamento entre a lembrança da marca e a sua participação de mercado. Revista Pretexto, Belo Horizonte, v. 13, n. 2, abr-jun. 2012. DOI: http://dx.doi.org/10.21714/pretexto.v13i2.1165

OLIVEIRA, I. C.; MOREIRA NETO, A. L. C. Comportamento do consumidor: a influência das mídias sociais na decisão de compra de produtos gamers. Revista de Pós-Graduação da Faculdade Cidade Verde, Maringá, v. 2, n. 1, ago. 2016.

PRODANOV, C. C.; FREITAS, E. C. Metodologia do trabalho científico [recurso eletrônico]: métodos e técnicas da pesquisa e do trabalho acadêmico. 2 ed. Novo Hamburgo: Feevale, 2013.

ROBERTS, J. A. Will the real socially responsible consumer please step forward? Business Horizons, v. 39, n. 1, p. 79-84, jan-fev.1996.

SCHARF, E. R.; SORIANO-SIERRA, E. J.; PRIM, D. Grandes marcas, ontem: o envelhecimento de marcas líderes. Revista de Administração FACES Journal, Belo Horizonte, v. 6, n. 2, maio-ago, 2007. DOI: http://dx.doi.org/10.21714/19846975FACES2007V6N2ART93

SCHIVINSKI, B.; DABROWSKI, D. The effect of social media communication on consumer perceptions of brands. Journal of Marketing Communications, v. 22, n. 2, p. 189-214, 2016. DOI: https://doi.org/10.1080/13527266.2013.871323

SEMPREBON, E.; PRADO, P. H. M. A influência do poder no relacionamento entre consumidor e marca. Revista de Administração Contemporânea, Curitiba, v. 20, n. 4, p. 389-411, jul-ago. 2016. DOI: http://dx.doi.org/10.1590/1982-7849rac2016140112

TRIOLA, M. F. Introdução à estatística. 12. ed. Rio de Janeiro: Ltc, 2017.

WOOD, L. Brands and brand equity: definition and management. Management decision, v. $38, \quad$ n. 9 , p. 662-669, nov. 2000 . DOI: https $/ /$ doi.org/10.1108/00251740010379100

VIEIRA, V. A. Comportamento do consumidor. Revista de Administração Contemporânea, Curitiba, v. 6, n. 3, p. 219-221, set-dez. 2002. 